\title{
Review of Performance of Impedance Based and Travelling Wave Based Fault Location Algorithms in Double Circuit Transmission Lines
}

\author{
Ankamma Rao Jonnalagadda, Gebreegziabher Hagos \\ Department of Electrical \& Computer Engineering, School of Engineering \& Technology, Samara University, Semera, Afar Region, Ethiopia
}

Email address:

jaraoeee04@gmail.com (A. R. Jonnalagadda), safehagos@gmail.com (G. Hagos)

To cite this article:

Ankamma Rao Jonnalagadda, Gebreegziabher Hagos. Review of Performance of Impedance Based and Travelling Wave Based Fault Location Algorithms in Double Circuit Transmission Lines. Journal of Electrical and Electronic Engineering. Vol. 3, No. 4, 2015 , pp. 65-69. doi: $10.11648 /$ j.jeee.20150304.11

\begin{abstract}
Parallel transmission lines or Double circuit transmission lines have been extensively utilized in modern power systems to enhance the reliability and security for transmission of electrical energy. This paper presents two fundamental algorithms: Impedance based, Travelling wave (TW) based algorithms for $100 \mathrm{~km}, 400 \mathrm{KV}$ Double circuit transmission lines. MATLAB/ Simulink software was used to implement these algorithms. The accuracy of fault location on power transmission line are reviewed for these two methods by varying various parameters like fault type, fault location on a given power system model.
\end{abstract}

Keywords: Fault Location, MATLAB, Impedance Based, Travelling Wave Based, Accuracy of Fault Location

\section{Introduction}

Location of faults in power transmission lines is one of main concerns for all electric utilities as the accurate fault location can help to restore the power supply in shortest possible time. Fault location methods are broadly classified as impedance based method which uses the steady state fundamental component of voltage and current values [1-6], Travelling wave(TW) based method which uses the incident and reflected TWs observed at measuring ends of the line[7-10], and knowledge based method which uses artificial neural network and/or pattern recognition techniques[11]. Conventional fault detection algorithms are designed based On current or voltage magnitude measurements. When a fault occurs on a transmission line it causes a sudden change in the current and voltage signals as well as measured impedances at the relay location. Increase of current magnitude or decrease of voltage/impedance magnitude could be considered as a measure to detect a system fault; these algorithms are dependent on various factors such as fault resistance and power system short circuit capacity. This paper describes two fundamental algorithms: Impedance based, Travelling wave (TW) based algorithms are implemented in $100 \mathrm{~km}, 400 \mathrm{KV}$ Double circuit transmission lines; it compares two algorithms by varying various parameters like fault type; fault location etc.

\section{Theory of Impedance Based Fault Location Algorithm}

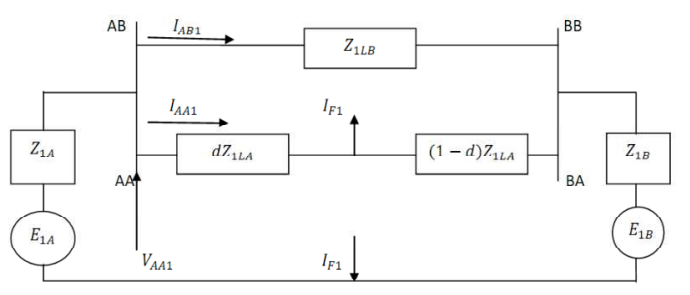

Fig. 1. Equivalent Positive sequence circuit diagram for double circuit transmission lines.

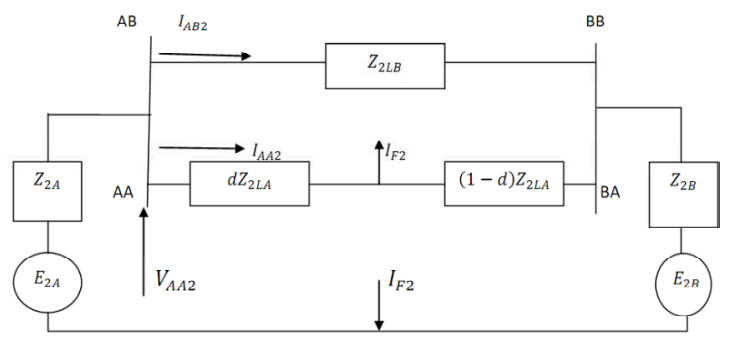

Fig. 2. Equivalent negative sequence circuit diagram for Double circuit transmission lines. 


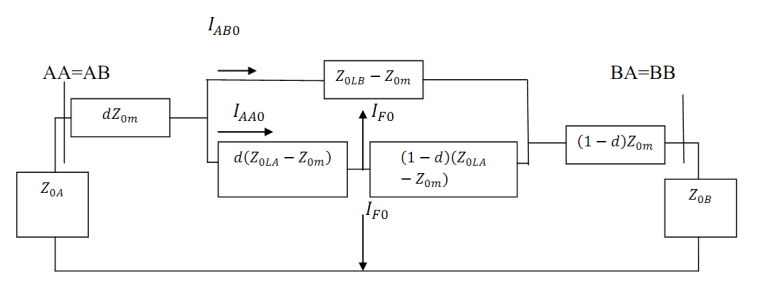

Fig. 3. Equivalent zero sequence circuit diagram for double circuit transmission lines.

To derive the Fault location algorithm, the fault loop composed according to the fault classified type is considered. This loop contains the faulted line segment (between points AA and F) and the fault path itself. A generalized model for the fault loop is stated as fallows

$$
V_{A A_{-} P}-d Z_{1 L A} * I_{A A_{-} P}-I_{F} * R_{F}=0
$$

Where

$$
I_{F}=a_{F 1} * I_{F 1}+a_{F 2} * I_{F 2}+a_{F 0} * I_{F 0}
$$

Fault loop voltages and current can be expressed interns of the local measurements and with using coefficients gathered in Table 1.

$$
\begin{gathered}
V_{A A_{-} P}=a_{1} V_{A A 1}+a_{2} V_{A A 2}+a_{0} V_{A A 0} \\
I_{A A_{-} P}=a_{1} I_{A A 1}+a_{2} I_{A A 2}+a_{0} \frac{z_{0 L A}}{Z_{1 L A}} I_{A A 0}+a_{0} \frac{z_{0 m}}{Z_{1 L A}} I_{A B 0}
\end{gathered}
$$

Table 1. Coefficients for determining signals defined in Equations (2) and (3).

\begin{tabular}{lccc}
\hline \multicolumn{1}{c}{ Fault Type } & $\boldsymbol{a}_{\mathbf{1}}$ & $\boldsymbol{a}_{\mathbf{2}}$ & $\boldsymbol{a}_{\mathbf{0}}$ \\
\hline$A G$ & 1 & 1 & 1 \\
$B G$ & $a^{2}$ & $a$ & 1 \\
$C G$ & $a$ & $a^{2}$ & 1 \\
$A B, A B G, A B C, A B C G$ & $1-a^{2}$ & $1-a$ & 0 \\
$B C, B C G$ & $a^{2}-a$ & $a-a^{2}$ & 0 \\
$C A, C A G$ & $a-1$ & $a^{2}-1$ & 0 \\
& $a=\exp (j 2 \pi / 3)$ & \\
\hline
\end{tabular}

Voltage drop across the fault path (as shown in the third term in Equation (1)) is expressed using sequence components of total fault current $\left(I_{\mathrm{F} 0}, I_{\mathrm{F} 1}, I_{\mathrm{F} 2}\right)$. Determining this voltage drop requires establishing the weighting coefficients. These coefficients can accordingly be determined by taking the boundary conditions for particular fault type. However, there is some freedom for that. Thus, it is proposed firstly to utilize this freedom for avoiding zero sequence quantities. This is well known that the zero sequence impedance of a line is considered as unreliable parameter. This is so due to dependence of this impedance upon the resistivity of a soil, which is changeable and influenced by weather conditions. Moreover, as a result of influence of overhead ground wires the zero sequence impedance is not constant along the line length. Thus, it is highly desirable to avoid completely the usage of zero sequence quantities when determining the voltage drop across the fault path. This can be accomplished by setting $I_{F 0}=0$ as shown in Table 2 , where the alternative sets of the weighting coefficients are gathered. Secondly, the freedom in establishing the weighting coefficients can be utilized for determining the preference for using particular quantities. The negative sequence (Table 2) or the positive sequence (Table 2) can be preferred.

For example, considering AG fault one has:

$$
\left|\begin{array}{l}
I_{F 0} \\
I_{F 1} \\
I_{F 2}
\end{array}\right|=\frac{1}{3} *\left|\begin{array}{ccc}
1 & 1 & 1 \\
1 & a & a^{2} \\
1 & a^{2} & a
\end{array}\right| *\left|\begin{array}{c}
I_{F A} \\
0 \\
0
\end{array}\right|
$$

Thus, symmetrical components of a fault current are:

$$
I_{F 0}=I_{F 1}=I_{F 2}=\frac{1}{3} * I_{F A}=I_{F}
$$

It follows from Equation (6) that the total faults current $\left(I_{F}=I_{F a}\right)$ can be expressed in the following alternative ways, depending on which symmetrical component is preferred:

$$
\begin{aligned}
& I_{F}=3 * I_{F 1} \\
& I_{F}=3 * I_{F 2} \\
& I_{F}=3 * I_{F 0} \\
& I_{F}=1.5 * I_{F 1}+1.5 * I_{F 2}
\end{aligned}
$$

Application of Equation (1) for fault location requires determining the positive and the negative sequence components of the fault path current. Considering the two different paths in the circuits of Fig.1 and Fig.2:- the faulted line segment adjacent to the local substation, the healthy line together with the remote segment of the faulted line, one obtains:

$$
\begin{aligned}
I_{F 1} & =\frac{I_{A A 1}-\frac{Z_{1 L B}}{Z_{1 L A}} * I_{A B 1}}{1-d} \\
I_{F 2} & =\frac{I_{A A 2}-\frac{Z_{2 L B}}{Z_{2 L A}} * I_{A B 2}}{1-d}
\end{aligned}
$$

Substituting Equation (11) and (12) in Equation (2)

$$
\begin{aligned}
I_{F} & =a_{F 1} * \frac{I_{A A 1}-\frac{Z_{1 L B}}{Z_{1 L A}} * I_{A B 1}}{1-d}+a_{F 2} * \frac{I_{A A 2}-\frac{Z_{2 L B}}{Z_{2 L A}} * I_{A B 2}}{1-d} \\
I_{F} & =\frac{a_{F 1} *\left(I_{A A 1}-\frac{Z_{1 L B}}{Z_{1 L A}} * I_{A B 1}\right)+a_{F 2} *\left(I_{A A 2}-\frac{Z_{2 L B}}{Z_{2 L A}} * I_{A B 2}\right)}{1-d}
\end{aligned}
$$

Let

$N_{12}=a_{F 1} *\left(I_{A A 1}-\frac{Z_{1 L B}}{Z_{1 L A}} * I_{A B 1}\right)+a_{F 2} * \frac{I_{A A 2}-\frac{Z_{2 L B}}{Z_{2 L A}} * I_{A B 2}}{1-d}$

Therefore

$$
I_{F}=\frac{N_{12}}{1-d}
$$

Substitute Equation (16) in Equation (1)

$$
V_{A A_{-} P}-d Z_{1 L A} * I_{A A_{-} P}-\frac{N_{12}}{1-d} * R_{F}=0
$$

Resolving (17) into real and imaginary parts gives:

$\operatorname{Re}\left(V_{A A_{-} P}\right)-d * \operatorname{Re}\left(Z_{1 L A} * I_{A A_{-} P}\right)-\frac{R_{F}}{1-d} * \operatorname{Re}\left(N_{12}\right)=0$ 
$\operatorname{Im}\left(V_{A A_{-} P}\right)-d * \operatorname{Im}\left(Z_{1 L A} * I_{A A_{-} P}\right)-\frac{R_{F}}{1-d} * \operatorname{Im}\left(N_{12}\right)=0$

Elimination of the agent $\left(\mathrm{R}_{\mathrm{F}} /(1-\mathrm{d})\right)$ yields the following formula for a sought distance to fault:

$$
\begin{aligned}
& \left|\begin{array}{ll}
\operatorname{Re}\left(Z_{1 L A} * I_{A A_{-} P}\right) & \operatorname{Re}\left(N_{12}\right) \\
\operatorname{Im}\left(Z_{1 L A} * I_{A A_{-} P}\right) & \operatorname{Im}\left(N_{12}\right)
\end{array}\right| *\left|\begin{array}{c}
d \\
\frac{R_{F}}{1-d}
\end{array}\right|=\left|\begin{array}{l}
\operatorname{Re}\left(V_{A A_{-} P}\right) \\
\operatorname{Im}\left(V_{A A_{-} P}\right)
\end{array}\right| \\
& d=\frac{\left|\begin{array}{ll}
\operatorname{Re}\left(V_{A A_{-} P}\right) & \operatorname{Re}\left(N_{12}\right) \\
I m\left(V_{A A_{P} P}\right) & \operatorname{Im}\left(N_{12}\right)
\end{array}\right|}{\left|\begin{array}{ll}
\operatorname{Re}\left(Z_{1 L A^{*} I_{A A} P}\right) & \operatorname{Re}\left(N_{12}\right) \\
I m\left(Z_{1 L A^{* I} A_{A} P}\right) & I m\left(N_{12}\right)
\end{array}\right|}
\end{aligned}
$$

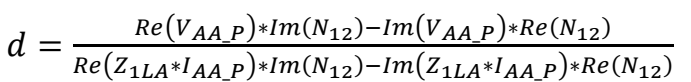

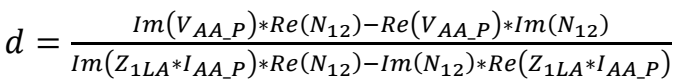

The formula (23) can be written down in a more even compact alternative form:

$$
d=\frac{\operatorname{Im}\left(V_{A A_{-} P N_{12}}{ }^{*}\right)}{\operatorname{Im}\left(Z_{1 L A^{*} I_{A A_{-}} P^{*} N_{12}}{ }^{*}\right)}
$$

\begin{tabular}{|c|c|c|c|c|c|c|}
\hline \multirow{2}{*}{ Fault type } & \multicolumn{3}{|c|}{ Set I } & \multicolumn{3}{|c|}{ Set II } \\
\hline & $a_{F 1}$ & $a_{F 2}$ & $a_{F 0}$ & $a_{F 1}$ & $a_{F 2}$ & $a_{F 0}$ \\
\hline$A G$ & 0 & 3 & 0 & 3 & 0 & 0 \\
\hline$B G$ & 0 & $-1.5+j 1.5 \sqrt{3}$ & 0 & $-1.5-j 1.5 \sqrt{3}$ & 0 & 0 \\
\hline$C G$ & 0 & $-1.5-j 1.5 \sqrt{3}$ & 0 & $-1.5+j 1.5 \sqrt{3}$ & 0 & 0 \\
\hline$A B$ & 0 & $1.5-j 0.5 \sqrt{3}$ & 0 & $1.5+j 0.5 \sqrt{3}$ & 0 & 0 \\
\hline$B C$ & 0 & $j \sqrt{3}$ & 0 & $-j \sqrt{3}$ & 0 & 0 \\
\hline$C A$ & 0 & $-1.5-j 0.5 \sqrt{3}$ & 0 & $-1.5+0.5 \sqrt{3}$ & 0 & 0 \\
\hline$A B G$ & $1.5+j 0.5 \sqrt{3}$ & $1.5-j 0.5 \sqrt{3}$ & 0 & $1.5+j 0.5 \sqrt{3}$ & $1.5-j 0.5 \sqrt{3}$ & 0 \\
\hline$B C G$ & $-j \sqrt{3}$ & $j \sqrt{3}$ & 0 & $-j \sqrt{3}$ & $j \sqrt{3}$ & 0 \\
\hline$C A G$ & $1.5-j 0.5 \sqrt{3}$ & $1.5+j 0.5 \sqrt{3}$ & 0 & $1.5-j 0.5 \sqrt{3}$ & $1.5+j 0.5 \sqrt{3}$ & 0 \\
\hline$A B C, A B C G$ & $1.5+j 0.5 \sqrt{3}$ & $1.5-j 0.5 \sqrt{3}$ & 0 & $1.5+j 0.5 \sqrt{3}$ & $1.5-j 0.5 \sqrt{3}$ & 0 \\
\hline
\end{tabular}

Table 2. Alternative sets of weighting coefficients.

\section{Traveling Wave Based Fault Location Algorithm}

The proposed fault location algorithm using Wavelet Transform is show in the following steps:

1. Get the signals from transducer output.

2. Transform the signals into modal domain.

3. Apply Discrete Wavelet Transform and obtain the Wavelet Transform Coefficients $\left(W_{m m}\right)$.

4. If the mode $0\left(W_{m m 0}\right)$ is zero, then the fault is identified as an ungrounded fault and the fault distance is given by the equation :

$$
\mathrm{d}=\left(\mathrm{v} \times \mathrm{t}_{\mathrm{d}}\right) / 2
$$

where $\mathrm{d}$ is the fault location from source $\mathrm{A}, v$ is the wave velocity of mode 1 having magnitude slightly less than velocity of light, and $t_{d}$ is the time gap between first two peaks of WTC of mode 1.

5. If the mode $0\left(W_{m m 0}\right)$ is nonzero, then the fault is identified as a grounded fault and the calculate the time gap $t_{d m}$ between the first peaks of mode 0 and mode 1 .

If $\operatorname{tdm}>\mathrm{tl} / 2$, then

$$
\begin{aligned}
& \mathrm{t}_{\mathrm{d}}=(2 l / v)-\mathrm{t}_{x} \\
& d=\left(v \times \mathrm{x} \mathrm{t}_{\mathrm{d}}{ }^{1}\right) / 2
\end{aligned}
$$

where $t l / 2$ is the travel time delay between mode 0 and mode 1 if the fault is located at the center of the line, $x$ is the distance to the fault, $v$ is the wave velocity of mode 1 , and $t x$ is the time delay between two consecutive peaks of the WTC mode 1 .
Else, the fault distance using (Fault is in second half section of line).

$$
\mathrm{d}=\left(\begin{array}{lll}
\mathrm{v} & \mathrm{x} & \mathrm{t}_{\mathrm{d}}
\end{array}\right) / 2
$$

\section{Power System Model}

The SimPowerSystem which is an extension to the simulink of MATLAB software was used to simulate the double end fed power system. The $100 \mathrm{~km}, 400 \mathrm{kV}$ Double circuit transmission line was modeled using distributed parameter model as shown in Fig.4

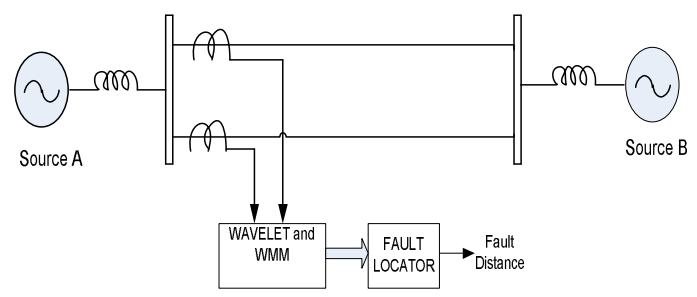

Fig. 4. Power System model.

The transmission line parameters are as follows: Positive Sequence Resistance, $\mathrm{R}_{1}: 0.0275 \Omega / \mathrm{km}$ Zero Sequence Resistance, $\mathrm{R}_{0}: 0.275 \Omega / \mathrm{km}$ Zero Sequence Mutual Resistance, $\mathrm{R}_{0 \mathrm{~m}}: 0.21 \Omega / \mathrm{km}$ Positive Sequence Inductance, $\mathrm{L}_{1}: 0.00102 \mathrm{H} / \mathrm{km}$ Zero Sequence Inductance, $\mathrm{L}_{0}: 0.003268 \mathrm{H} / \mathrm{km}$ Zero Sequence Mutual Inductance, $\mathrm{L}_{0 \mathrm{~m}}: 0.0020 \mathrm{H} / \mathrm{km}$ Positive Sequence Capacitance, $\mathrm{C}_{1}: 13 \mathrm{e}^{-0.009} \mathrm{~F} / \mathrm{km}$ Zero Sequence Capacitance, $\mathrm{C}_{0}: 8.5 \mathrm{e}^{-0.009} \mathrm{~F} / \mathrm{km}$ Zero Sequence mutual Capacitance, $\mathrm{C}_{\mathrm{om}}:-5 \mathrm{e}^{-009} \mathrm{~F} / \mathrm{km}$ 


\section{Simulation Results}

The simulation is carried out for these algorithms by varying various fault parameters like fault type, fault location etc. The accuracy of fault location of these three algorithms are compared and shown in Table. 3 .

Table 3. Results of two algorithms.

\begin{tabular}{llllll}
\hline \multirow{2}{*}{ Fault Type } & $\begin{array}{l}\text { Actual } \\
\text { location }\end{array}$ & fault & \multicolumn{2}{l}{ Impedance based Method } & \multicolumn{2}{c}{ Travelling wave based Method } \\
\cline { 3 - 6 } & $\mathbf{d}_{\text {esti }}$ & Error\% & \multicolumn{2}{c}{$\mathbf{d}_{\text {esti }}$} & 9.911 \\
\hline E1G & 10 & 9.6896 & $0.3104 \%$ & 19.944 & $0.089 \%$ \\
B1G & 20 & 19.7514 & $0.2486 \%$ & 29.96 & $0.040 \%$ \\
C2G & 30 & 29.3602 & $0.6398 \%$ & 39.997 & $0.003 \%$ \\
A2B2 & 40 & 39.938 & $0.062 \%$ & 49.944 & $0.056 \%$ \\
B2C2 & 50 & 49.3868 & $0.6132 \%$ & 59.039 & $0.961 \%$ \\
C1A1 & 60 & 59.248 & $0.752 \%$ & 69.901 & $0.099 \%$ \\
A2B2G & 70 & 69.9129 & $0.0871 \%$ & 79.879 & $0.121 \%$ \\
B1C1G & 80 & 78.9692 & $1.0308 \%$ & 84.963 & $0.037 \%$ \\
C1A1G & 85 & 84.9617 & $0.0383 \%$ & 89.928 & $0.072 \%$ \\
A1B1C1,A1B1C1G & 90 & 89.94 & $0.06 \%$ & \\
\hline
\end{tabular}

The fault location error is calculated as

$$
\operatorname{Error}(\%)=\frac{\mid \text { Calculated Fault Location-Actual Fault Location } \mid}{\text { Total Line Length }} * 100
$$

\section{Conclusion}

The use of double circuit lines are becoming common when constructing and updating newlines. In this paper, two fundamental algorithms: Impedance based, Travelling wave(TW) algorithms for $100 \mathrm{~km}, 400 \mathrm{KV}$ Double circuit transmission lines are implemented using Matlab Simulink and programing. The performance of these two algorithms are reviewed by varying various parameters like fault type, fault location etc. The simulation results show that all ten types of faults are correctly located and travelling wave (TW) based algorithm locates faults with accuracy less than $0.5 \%$ and Impedance based algorithms locates faults with accuracy less than $2 \%$.

\section{Nomenclature}

$D$ : Estimated distance to the fault (units: p.u)

$V_{A A P}$ : Fault loop voltage composed according to fault, Type for double circuit line

$I_{A A_{-} P}$ :Fault loop current composed according to fault, type for double Circuit line.

$I_{F}:$ Total fault current

$a_{F 0}, a_{F 1}, a_{F 2}$ :Weighting coefficients (complex numbers), dependent on fault type and the assumed priority for using particular symmetrical components

$I_{F 0}, \quad I_{F 1}, I_{F 2}$ : Zero, positive and negative sequence components of total fault current, which are to be calculated or estimated.

$Z_{1 A}, Z_{1 B}$ : Positive sequence source impedances at terminals $A$ and $\mathrm{B}$ respectively.

$Z_{2 A}, Z_{2 B}$ : Negative sequence source impedances at terminals $\mathrm{A}$ and $\mathrm{B}$ respectively .

$E_{1 A}, E_{l B}$ : Positive sequence source voltages at terminals A and $\mathrm{B}$ respectively.
$Z_{I L A}$ : Positive sequence impedance of the faulted line $A A$

$Z_{O L A}:$ Zero sequence impedance the of faulted line $A A$

$I_{A A 1}, I_{A A 2}, I_{A A 0}$ : Total sequence currents from faulted line (AA)

$V_{A A 1}, V_{A A 2}, V_{A A O}$ : Total sequence voltages from faulted line $(A A)$

$I_{A B 1}, I_{A B 2}, I_{A B 0}$ : Total sequence currents from healthy line $(A B)$

\section{References}

[1] L. Eriksson, M. M. Saha, and G. D. Rockefeller, “An accurate fault locator with compensation for apparent reactance in the fault resistance resulting from remote-end infeed," IEEE Trans. Power App. Syst., vol. PAS-104,no. 2, pp. 423 436, Feb. 1985.

[2] Izykowski J, Rosolowski E, Saha MM (2004) “Locating faults in parallel transmission lines under availability of complete measurements at one end". IEE Proc - Gener Transm Distrib 151(2):268-273.

[3] M. S. Sachdev and R. Agarwal, "A technique for estimating transmission line fault locations from digital impedance relay measurements," IEEE Trans. Power Del., vol. 3, no. 1, pp. 121-129, Jan. 1988.

[4] Saha MM, Wikstrom K, Izykowski J, Rosolowski E (2001) "New fault location algorithm for parallel lines". In: Proc of 7th Int Conf on Developments in Power System Protection - DPSP, IEE CP476 pp 407-410.

[5] Wiszniewski A. "Accurate fault impedance locating algorithm". IEE Proc C1983:130(6):311-5.

[6] Izykowski J, Kawecki R, Rosolowski E (2002) “Accurate location of faults in parallel transmission lines under availability of measurements from one circuit only".In: Proc of Power Systems Computation Conference -PSCC'02 (CD ROM), Sevilla,paper 6. 
[7] Magnago FH, Abur A (1998) "Fault location using wavelets". IEEE Trans on Power Deliv 13(4):1475-1480.

[8] Abur A, Magnago FH (2000) Use of time delays between modal components in wavelet based fault location. Int J Electr Power and Energy Syst 22(6):397-403.

[9] V.S.Kale, S.R.Bhide, P.P.Bedekar, Faulted Phase Selection Based on Wavelet Analysis of Traveling Waves", International Journal of Computer and Electrical Engineering, Vol. 3, No. 3, June 2011.
[10] AnkammaRao J, BizuayehuBogale .Double Circuit Transmission Line Fault Distance Location using Wavelet Transform and WMM Technique ",International Journal of Science and Research (IJSR), Vol.4, Issue.1,January-2015.

[11] Anamika Jain, Kale VS, Thoke AS. Application of artificial neural networks to transmission line faulty phase selection and fault distance location. In: IASTED, Chiang Mai, Thailand; 29-31 March 2006. p. 262-7.

[12] MATLAB user's guide, The Math Works Inc., Natick, MA. 